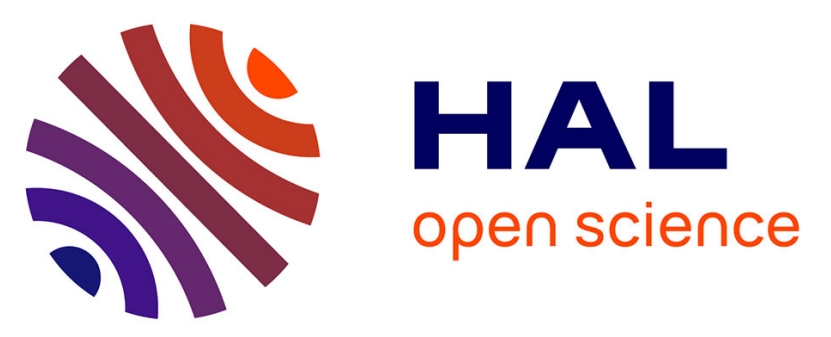

\title{
A phase II, randomized, multicenter study to assess the efficacy, safety, and tolerability of zibotentan (ZD4054) in combination with pemetrexed in patients with advanced non-small cell lung cancer
}

Christos Chouaid, Faith Nathan, Kristine Pemberton, Thomas Morris

\section{To cite this version:}

Christos Chouaid, Faith Nathan, Kristine Pemberton, Thomas Morris. A phase II, randomized, multicenter study to assess the efficacy, safety, and tolerability of zibotentan (ZD4054) in combination with pemetrexed in patients with advanced non-small cell lung cancer. Cancer Chemotherapy and Pharmacology, 2010, 67 (5), pp.1203-1208. 10.1007/s00280-010-1538-z . hal-00651658

\author{
HAL Id: hal-00651658 \\ https://hal.science/hal-00651658
}

Submitted on 14 Dec 2011

HAL is a multi-disciplinary open access archive for the deposit and dissemination of scientific research documents, whether they are published or not. The documents may come from teaching and research institutions in France or abroad, or from public or private research centers.
L'archive ouverte pluridisciplinaire HAL, est destinée au dépôt et à la diffusion de documents scientifiques de niveau recherche, publiés ou non, émanant des établissements d'enseignement et de recherche français ou étrangers, des laboratoires publics ou privés. 


\section{A Phase II, randomized, multicenter study to assess the efficacy, safety and tolerability of zibotentan (ZD4054) in combination with pemetrexed in patients with advanced non-small cell lung cancer}

Christos Chouaid, ${ }^{1 *}$ Faith Nathan, ${ }^{2}$ Kristine Pemberton, ${ }^{2}$ Thomas Morris ${ }^{2}$

${ }^{1}$ Hôpital St-Antoine, Paris, France

${ }^{2}$ AstraZeneca, Alderley Park, Macclesfield, UK

${ }^{*}$ Corresponding author:

Address: Service de Pneumologie, Hôpital Saint Antoine, 184 Rue du Faubourg, Saint-Antoine, 75571 Paris Cedex 12, France

Phone: +33 (0)1 49282516

Fax: $+33(0) 149282283$

Email: christos.chouaid@sat.aphp.fr

Short communication

Word count: 2296

No of figures: 1

No of tables: 2 


\section{Abstract}

Purpose: This study evaluated overall survival (OS) of patients with advanced nonsquamous NSCLC following treatment with the specific endothelin A receptor antagonist, zibotentan in combination with pemetrexed compared with pemetrexed monotherapy.

Methods: In this double-blind, placebo-controlled study, patients with advanced NSCLC with non-squamous histology who had failed first-line platinum-based chemotherapy were randomized to receive either once-daily zibotentan $10 \mathrm{mg}$ in combination with 3-weekly pemetrexed $500 \mathrm{mg} / \mathrm{m}^{2}$ or placebo plus 3-weekly pemetrexed $500 \mathrm{mg} / \mathrm{m}^{2}$. OS was calculated as the interval from date of randomization to date of death from any cause. Safety and tolerability were evaluated by recording the incidence of adverse events (AE) according to Common Toxicity Criteria for AEs (CTCAE).

Results: Sixty-six patients were randomized and completed the study (zibotentan plus pemetrexed, $n=30$; placebo plus pemetrexed, $n=36$ ). At the data cut-off, a total of 44 deaths had occurred, 20 and 24 in the zibotentan and placebo groups, respectively. No significant difference in OS was observed between the zibotentan and placebo treatment groups $(\mathrm{HR}, 1.13 ; 80 \% \mathrm{Cl} 0.77,1.67 ; P=0.69)$. The majority of AEs were of CTCAE grade 1 or 2 , and the most commonly reported AE in both treatment groups was anemia ( $23 \%$ and $25 \%$ of patients in the zibotentan and placebo groups, respectively).

Conclusions: There was no survival signal in patients with NSCLC following treatment with zibotentan in combination with pemetrexed. No new issues related to safety for either zibotentan or pemetrexed were identified.

Word count: 237

Key words: Zibotentan, endothelin, NSCLC, cancer, clinical trial 


\section{Introduction}

Lung cancer has the highest mortality rate of all cancers, with non-small cell lung cancer (NSCLC) accounting for approximately $85 \%$ of all lung cancers [1]. The majority of patients with NSCLC present with locally advanced inoperable or metastatic disease. Historically, patients who are not candidates for definitive locoregional therapy, receive a finite number of cycles of first-line chemotherapy with platinum doublets [2]. Second-line treatment options include pemetrexed, which has been reported to have similar efficacy and a favorable safety profile compared with docetaxel [3]. The epidermal growth factor receptor (EGFR) tyrosine kinase inhibitors erlotinib and gefitinib have also demonstrated monotherapy activity in previously treated patients with advanced NSCLC. Erlotinib demonstrated an improvement in overall survival (OS) of 2 months in a placebo-controlled Phase III trial in the secondline setting [4], and more recently, gefitinib was shown to be non-inferior to docetaxel in terms of OS [5] and demonstrated a longer progression-free survival in pretreated patients with advanced NSCLC who had an EGFR mutation [6]. Although several new treatments have been identified, there has been minimal improvement in median survival of patients with NSCLC [7].

Endothelin-1 (ET-1), acting through the endothelin $A\left(E T_{A}\right)$ receptor, is implicated in the development of several cancer types through activation of pathways involved in proliferation, migration, invasion, epithelial-mesenchymal transition, osteogenesis, and angiogenesis, while activation of the endothelin $B\left(E T_{B}\right)$ receptor may induce cell death by apoptosis, promote ET-1 clearance and inhibit tumor progression [8]. Tumor tissues from patients with NSCLC have been shown to express ET-1, which has been correlated with poor prognosis in patients with this disease [9]. Furthermore, $\mathrm{ET}_{\mathrm{B}}$ receptor mRNA expression is reduced in NSCLC tissues [10]. Therefore, specific blockade of the $\mathrm{ET}_{\mathrm{A}}$ receptor may be a potential target for the treatment of patients with NSCLC.

Zibotentan (ZD4054) is a specific $\mathrm{ET}_{\mathrm{A}}$ receptor antagonist, which has demonstrated antitumor activity, both as a single agent and in combination, in a range of preclinical cancer models [8]. A promising signal for improved survival was observed in a Phase 
II monotherapy trial in patients with metastatic castration-resistant prostate cancer (CRPC) [11, 12]. Zibotentan is being further assessed in a large Phase III clinical trial program in men with CRPC $[11,12]$. Zibotentan efficacy is also being tested in a number of other cancer types.

The primary objective of this study was to evaluate the relative effect of zibotentan plus pemetrexed versus pemetrexed alone on OS in patients with locally advanced or metastatic non squamous NSCLC who had failed first-line platinum-based chemotherapy. OS was selected as the primary endpoint in this study because a survival advantage was observed following treatment with zibotentan in a Phase II study of patients with castration-resistant prostate cancer. Secondary objectives included assessment of the number of patients with a disease progression event, time to clinical progression (TTP), and safety and tolerability of the combination regimen.

\section{Methods}

\section{Study design and participants}

In this double-blind, placebo-controlled, Phase II study, patients aged $\geq 18$ years of age with locally advanced or metastatic NSCLC without predominantly squamous histology, and a World Heath Organization performance status of $0-2$, who had failed one prior platinum-based chemotherapy regimen were enrolled. This study was restricted to patients with predominantly non-squamous NSCLC histology as pemetrexed is now approved in Europe for the treatment of advanced nonsquamous NSCLC only. Exclusion criteria included treatment with pemetrexed within the last 12 months, prior therapy with an $\mathrm{ET}_{\mathrm{A}}$ or $\mathrm{ET}_{\mathrm{B}}$ receptor antagonist, radiotherapy to the primary tumor within 4 weeks of study entry, use of CYP450 inducers within 2 weeks of randomization (dexamethasone was permitted as premedication for pemetrexed), brain metastases or spinal chord compression unless treated and stable without steroids for 1 month, and any significant bone marrow, renal or hepatic impairment. 
Patients were randomized in a $1: 1$ ratio to receive once-daily zibotentan $10 \mathrm{mg}$ plus 3-weekly pemetrexed $500 \mathrm{mg} / \mathrm{m}^{2}$ or once-daily placebo plus 3-weekly pemetrexed $500 \mathrm{mg} / \mathrm{m}^{2}$. All patients also received the appropriate supplementary medications. Patients were evaluated every week for the first 3 weeks of the study, and then on a 3-weekly basis whilst continuing on study medication until data cut-off for survival was reached. In addition, there was one intermediate mandatory tumor assessment visit (MTAV) to assess disease progression, which occurred approximately 3 months following the randomization of the last patient. This study was designed as a randomized screening study to quantify the level of risk entailed for further development. Thus, the type I and type II errors were adjusted to be less constrained so that the targeted treatment benefit would be apparent while the sample size remained reasonable [13]. A study with at least $80 \%$ power to detect a hazard ratio (HR) of 0.50 at the 2 -sided, $20 \%$ significance level required approximately 38 death events. Assuming a median survival of 8 months for pemetrexed [3], recruitment of 64 patients in 9 months was expected to yield approximately 38 death events after approximately 12 months following randomization of the last patient.

All patients provided written informed consent. The study was approved by the independent ethics committee for each trial center, and was conducted in accordance with the Declaration of Helsinki [14].

\section{Assessments}

OS was calculated as the interval from the date of randomization to the date of death from any cause. The efficacy of zibotentan in combination with pemetrexed was evaluated by assessment of objective disease progression measured using Response Evaluation Criteria In Solid Tumors (RECIST) version 1.0 [15] and/or TTP on or before the intermediate MTAV, and death by any cause. Safety and tolerability were evaluated by recording the incidence of adverse events (AEs) according to the Common Toxicity Criteria for AEs (CTCAE) version 3.0, and by monitoring b-type natriuretic peptide (BNP), weight, hematology and clinical chemistry.

\section{Statistical analysis}


OS data were analyzed using a Cox proportional hazards regression model with a factor accounting for treatment group. To evaluate the secondary objective of the efficacy of zibotentan in combination with pemetrexed versus pemetrexed alone, a primary event count analysis, TTP analysis and a sensitivity analysis were performed. The primary event count analysis compared the number of patients who had progressed or died by the MTAV using a logistic-regression model with a complementary log-log function, including a factor for treatment group. The TTP analysis was performed in support of the progression event count analysis using a Cox proportional hazards regression model with a factor accounting for treatment group. A sensitivity analysis was performed, which assumed that the patients without a MTAV in the zibotentan and placebo groups had progressed and not progressed, respectively. The estimated $\mathrm{HR}, 80 \%$ confidence interval $(\mathrm{Cl})$ and $P$-value for OS and the efficacy analyses were calculated.

\section{Results}

Between 12 August 2008 and 17 January 2010 (data cut-off), 66 patients were randomized and completed the study. Thirty patients (45\%) received zibotentan plus pemetrexed and 36 (55\%) received placebo plus pemetrexed. All subjects were Caucasian and the mean (SD) age was 58 (10) and 57 (12) years in the zibotentan and placebo groups, respectively (Table 1). The majority of patients (83\%) in both arms had a WHO performance status of 1 and had adenocarcinoma, reflecting the predominance of this histology type, however, there were a number of patients with undifferentiated or large cell tumor types (Table 1). There were some minor baseline differences between treatment groups including time since diagnosis of advanced disease $<1$ year (zibotentan $53 \%$ and placebo $81 \%$ ), metastasis in distant lymph nodes and bone (zibotentan $47 \%$ and $30 \%$, respectively; placebo $36 \%$ and $19 \%$, respectively), habitual smokers (zibotentan $17 \%$ and placebo $31 \%$ ) and previous taxane therapy (zibotentan $40 \%$ and placebo $31 \%$ ). A total of 26 patients $(87 \%$ ) in the zibotentan group and 32 patients (89\%) in the placebo group discontinued treatment prior to the data cut-off. After disease progression subsequent cancer therapy was administered to six patients receiving zibotentan ( $n=1$ chemotherapy, $\mathrm{n}=3$ radiotherapy, $\mathrm{n}=1$ radiotherapy plus targeted therapy, $\mathrm{n}=1$ targeted therapy plus 
immunotherapy) and 11 patients receiving placebo ( $n=4$ chemotherapy, $n=2$ radiotherapy, $n=1$ targeted therapy, $n=1$ osteoclast inhibitor, $n=1$ chemotherapy plus radiotherapy, $n=1$ radiotherapy plus chemotherapy, $n=1$ targeted therapy plus immunotherapy). At data cut-off, eight patients ( $n=4$ in each group) were continuing on study therapy as they were judged to be deriving a clinical benefit by the investigator.

At the data cut-off, a total of 44 deaths had occurred, 20 and 24 in the zibotentan and placebo groups, respectively. Of these, 18 deaths in the zibotentan group and 22 deaths in the placebo group were disease-related, not due to an AE with an outcome of death. There was no significant difference in OS between the zibotentan and placebo treatment groups $(\mathrm{HR}, 1.13 ; 80 \% \mathrm{Cl} 0.77,1.67 ; P=0.69$; Figure 1a). The primary event count analysis indicated that there was no difference between the two treatment groups in the number of patients with a disease progression event on or before the MTAV (19 [63\%] in the zibotentan group and 26 [72\%] in the placebo group) (HR, $0.78 ; 80 \% \mathrm{Cl} 0.52,1.18 ; P=0.44)$. For this analysis, patients were assumed to not have progressed if they were not assessed at the MTAV (five patients in the zibotentan group and two patients in the placebo group were not assessed). Following an additional sensitivity analysis, which assumed that the patients without a MTAV in the zibotentan group had progressed and the patients in the placebo group without a MTAV had not progressed, the HR was $1.26(80 \% \mathrm{Cl}$ $0.85,1.87 ; P=0.46$ ). The median TTP was longer in the zibotentan group (110 days) compared with the placebo group (87 days; Figure $1 b$ ).

Investigator assessed RECIST responses were evaluated in 18 patients in the zibotentan group and 30 patients in the placebo group. Two patients in the placebo group had a partial response and 13 patients in each group had stable disease. The remaining patients who were assessed had progressive disease (five patients in the zibotentan group and 15 patients in the placebo group).

For patients receiving once-daily zibotentan $10 \mathrm{mg}$ and pemetrexed, mean (range) exposure was $136(7-427)$ and 135 (21-428) days for zibotentan and pemetrexed, 
respectively. Patients receiving placebo plus pemetrexed had mean (range) exposures of 139 (7-406) and 137 (21-401) days, respectively. The majority of patients in both treatment groups reported at least one AE (zibotentan 76.7\%; placebo $69.4 \%$ ). The majority of AEs were of CTCAE grade 1 or 2; eight patients $(27 \%)$ in the zibotentan group and 12 patients $(33 \%)$ in the placebo group had an $\mathrm{AE}$ of CTCAE grade $\geq 3$ (Table 2). The most commonly reported AE in both treatment groups was anemia, which was reported in $23 \%$ of patients in the zibotentan group and $25 \%$ of patients in the placebo group. Other commonly reported AEs were nausea $(17 \%)$ and peripheral edema (13\%) in the zibotentan group and neutropenia $(14 \%)$ in the placebo group. Four patients $(13 \%)$ in the zibotentan group and seven patients (19\%) in the placebo group experienced a serious $A E$, none of which were considered to be related to the study treatment. Four patients, two in each treatment group, had a serious AE that led to death (zibotentan, pancytopenia and dyspnea; placebo, febrile bone marrow aplasia and upper gastrointestinal hemorrhage). Two (7\%) patients receiving zibotentan discontinued treatment due to AEs (headache and dyspnea) and three (8\%) patients receiving placebo discontinued treatment due to AEs (brain metastasis ['metastases to central nervous system' was reported as an $\mathrm{AE}]$, febrile bone marrow aplasia and abdominal pain, anemia, renal failure and upper gastrointestinal hemorrhage). 


\section{Discussion}

In this study, there was no evidence of efficacy of zibotentan in patients with locally advanced or metastatic NSCLC as indicated by the similar OS and progression results between patients receiving zibotentan plus pemetrexed versus those receiving placebo plus pemetrexed. The additional sensitivity analysis, which assumed that the patients without a MTAV in the zibotentan group had progressed and patients in the placebo group had not progressed demonstrated that the primary analysis was potentially biased in favor of the zibotentan treatment group, confirming the lack of efficacy of zibotentan in this patient population. Some small differences in the baseline characteristics of patients between the two treatment groups were observed, however this was to be expected in a study of this size. Of these imbalances, some characteristics (ex-smoker, habitual smoker, female gender) favored zibotentan whilst others (time since diagnosis of advanced disease $<1$ year) favored placebo. These differences were not considered to have had an impact on the results of the study.

The majority of trials in advanced NSCLC have, due to time constraints, used TTP as the primary clinical endpoint. However, results from this study have demonstrated that an OS result can be gained in this patient population in a relatively short timeframe. This suggests that time limitation may not be a valid rationale for using TTP as the primary endpoint in trials of patients with advanced NSCLC, and that OS could feasibly be utilized as the primary endpoint in this patient population with, TTP as a secondary endpoint.

No new safety concerns were identified for zibotentan in this study, the AE profile was consistent with previous clinical trials of this agent and other $E T_{A}$ receptor antagonists [11, 16]. The safety profile of pemetrexed monotherapy was also reflective of earlier experience [17], and the safety profile of the combination regimen was consistent with that of each agent used as a monotherapy with no additional safety concerns identified. 
In conclusion, this study does not appear to demonstrate any survival or progression advantage of zibotentan $10 \mathrm{mg}$ in combination with pemetrexed for patients with advanced NSCLC (adenocarcinoma) in the second-line setting. While this could reflect the low number of patients in the study, the absence of any favorable trends do not support further clinical development in this disease setting. The safety profile of zibotentan in this study was consistent with previous studies and no new toxicity or tolerability issues were identified.

\section{Acknowledgments}

We thank Dr Claire Routley from Mudskipper who provided editorial assistance funded by AstraZeneca. 
Table 1. Patient characteristics

\section{Zibotentan $(n=30) \quad$ Placebo $(n=36)$}

\begin{tabular}{|c|c|c|}
\hline \multicolumn{3}{|l|}{ Age, years } \\
\hline Mean (SD) & $57.5(10.4)$ & $56.6(12.1)$ \\
\hline Range & $24-70$ & $29-77$ \\
\hline \multicolumn{3}{|l|}{ Sex, n (\%) } \\
\hline Male & $19(63)$ & $28(78)$ \\
\hline Female & $11(37)$ & $8(22)$ \\
\hline \multicolumn{3}{|l|}{ Race, n (\%) } \\
\hline Caucasian & $30(100)$ & $36(100)$ \\
\hline \multicolumn{3}{|l|}{ Type of NSCLC, n (\%) } \\
\hline Adenocarcinoma & $25(83)$ & $31(86)$ \\
\hline Large cell carcinoma & $3(10)$ & $3(8)$ \\
\hline Undifferentiated & $2(7)$ & $2(6)$ \\
\hline \multicolumn{3}{|c|}{ WHO performance status, $\mathrm{n}(\%)^{*}$} \\
\hline 0 & $3(10)$ & $5(14)$ \\
\hline 1 & $25(83)$ & $30(83)$ \\
\hline 2 & $2(7)$ & $1(3)$ \\
\hline \multicolumn{3}{|c|}{ Number of distant metastatic sites, $\mathrm{n}(\%)$} \\
\hline 0 & $3(10)$ & $5(14)$ \\
\hline 1 & $4(13)$ & $9(25)$ \\
\hline$>1$ & $23(77)$ & $22(61)$ \\
\hline \multicolumn{3}{|c|}{ Location of metastasis, $\mathrm{n}(\%)$} \\
\hline Distant lymph nodes & $14(47)$ & $13(36)$ \\
\hline Bones & $9(30)$ & 7 (19) \\
\hline Skin/soft tissue & 0 & $2(6)$ \\
\hline Other & $24(80)$ & $27(75)$ \\
\hline \multicolumn{3}{|c|}{ Time since diagnosis of advanced disease } \\
\hline$<1$ year & $16(53)$ & $29(80)$ \\
\hline$\geq 1$ year & $14(47)$ & $7(19)$ \\
\hline \multicolumn{3}{|l|}{ Smoking status } \\
\hline Non smoker & $11(37)$ & $12(33)$ \\
\hline Ex smoker & $14(47)$ & $13(36)$ \\
\hline Occasional smoker & 0 & 0 \\
\hline Habitual smoker & $5(17)$ & $11(31)$ \\
\hline
\end{tabular}

SD, standard deviation; *WHO performance status, $0=$ normal activity, $1=$ restricted activity, $2=$ in bed $\geq 50 \%$ of the time 
Table 2. Adverse events reported by $\geq 10 \%$ patients in either treatment group

\begin{tabular}{lcc}
\hline & \multicolumn{2}{c}{ Patients with AEs, $\mathrm{n}(\%)$} \\
\cline { 2 - 3 } Adverse events (AEs) & $\begin{array}{c}\text { Zibotentan plus } \\
\text { pemetrexed } \\
(\mathrm{n}=30)\end{array}$ & $\begin{array}{c}\text { Placebo plus } \\
\text { pemetrexed } \\
(\mathrm{n}=36)\end{array}$ \\
\hline Any AE & $23(76.7)$ & $25(69.4)$ \\
Anemia & $7(23.3)$ & $9(25)$ \\
Nausea & $5(16.7)$ & $2(5.6)$ \\
Peripheral edema & $4(13.3)$ & $1(2.8)$ \\
Decreased weight & $3(10)$ & $3(8.3)$ \\
Rash & $3(10)$ & $1(2.8)$ \\
Headache & $3(10)$ & $1(2.8)$ \\
Increased brain natriuretic peptide & $3(10)$ & 0 \\
Neutropenia & $1(3.3)$ & $5(13.9)$ \\
\hline
\end{tabular}


Figure legend

Fig. 1 Kaplan-Meier curves of (a) overall survival and (b) time to progression* 


\section{References}

1. Jemal A, Siegel R, Ward E, Hao Y, Xu J, Thun MJ (2009) Cancer statistics, 2009. CA Cancer J Clin 59:225-249.

2. Hirsh V (2010) Systemic therapies in metastatic non-small-cell lung cancer with emphasis on targeted therapies: the rational approach. Curr Oncol 17:13-23.

3. Hanna N, Shepherd FA, Fossella FV, Pereira JR, De Marinis F, von Pawel J, Gatzemeier U, Tsao TC, Pless M, Muller T, Lim HL, Desch C, Szondy K, Gervais R, Shaharyar, Manegold C, Paul S, Paoletti P, Einhorn L, Bunn PA, Jr. (2004) Randomized phase III trial of pemetrexed versus docetaxel in patients with nonsmall-cell lung cancer previously treated with chemotherapy. J Clin Oncol 22:15891597.

4. Shepherd FA, Rodrigues Pereira J, Ciuleanu T, Tan EH, Hirsh V, Thongprasert S, Campos D, Maoleekoonpiroj S, Smylie M, Martins R, van Kooten M, Dediu M, Findlay B, Tu D, Johnston D, Bezjak A, Clark G, Santabarbara P, Seymour L (2005) Erlotinib in previously treated non-small-cell lung cancer. N Engl J Med 353:123-132.

5. Kim ES, Hirsh V, Mok T, Socinski MA, Gervais R, Wu YL, Li LY, Watkins CL, Sellers MV, Lowe ES, Sun Y, Liao ML, Osterlind K, Reck M, Armour AA, Shepherd FA, Lippman SM, Douillard JY (2008) Gefitinib versus docetaxel in previously treated non-small-cell lung cancer (INTEREST): a randomised phase III trial. Lancet 372:1809-1818.

6. Douillard JY, Shepherd FA, Hirsh V, Mok T, Socinski MA, Gervais R, Liao ML, Bischoff H, Reck M, Sellers MV, Watkins CL, Speake G, Armour AA, Kim ES (2010) Molecular predictors of outcome with gefitinib and docetaxel in previously treated non-small-cell lung cancer: data from the randomized phase III INTEREST trial. J Clin Oncol 28:744-752.

7. Katzel JA, Fanucchi MP, Li Z (2009) Recent advances of novel targeted therapy in non-small cell lung cancer. J Hematol Oncol 2:2.

8. Growcott JW (2009) Preclinical anticancer activity of the specific endothelin A receptor antagonist ZD4054. Anticancer Drugs 20:83-88.

9. Boldrini L, Gisfredi S, Ursino S, Faviana P, Lucchi M, Melfi F, Mussi A, Basolo F, Fontanini $G$ (2005) Expression of endothelin-1 is related to poor prognosis in nonsmall cell lung carcinoma. Eur J Cancer 41:2828-2835.

10. Knight LJ, Burrage J, Bujac SR, Haggerty C, Graham A, Gibson NJ, Ellison G, Growcott JW, Brooks AN, Hughes AM, Xinarianos G, Nikolaidis G, Field JK, Liloglou T (2009) Epigenetic silencing of the endothelin-B receptor gene in nonsmall cell lung cancer. Int J Oncol 34:465-471.

11. James ND, Caty A, Payne H, Borre M, Zonnenberg BA, Beuzeboc P, McIntosh S, Morris T, Phung D, Dawson NA (2010) Final safety and efficacy analysis of the specific endothelin A receptor antagonist zibotentan (ZD4054) in patients with 
metastatic castration-resistant prostate cancer and bone metastases who were pain-free or mildly symptomatic for pain: a double-blind, placebo-controlled, randomized Phase II trial. BJU Int 106:966-973.

12. Fizazi K, Miller K (2009) Specific endothelin-A receptor antagonism for the treatment of advanced prostate cancer. BJU Int 104:1423-1425.

13. Rubinstein LV, Korn EL, Freidlin B, Hunsberger S, Ivy SP, Smith MA (2005) Design issues of randomized phase II trials and a proposal for phase II screening trials. $J$ Clin Oncol 23:7199-7206.

14. World Medical Association (WMA). Declaration of Helsinki. Ethical principles for medical research involving human subjects. Adopted by the 18th WMA General Assembly, Helsinki, Finland, June. 1964. Available at: http://www.wma.net/en/30publications/10policies/b3/index.html.

15. Therasse P, Arbuck SG, Eisenhauer EA, Wanders J, Kaplan RS, Rubinstein L, Verweij J, Van Glabbeke M, van Oosterom AT, Christian MC, Gwyther SG (2000) New guidelines to evaluate the response to treatment in solid tumors. European Organization for Research and Treatment of Cancer, National Cancer Institute of the United States, National Cancer Institute of Canada. J Natl Cancer Inst 92:205216.

16. Carducci MA, Saad F, Abrahamsson PA, Dearnaley DP, Schulman CC, North SA, Sleep DJ, Isaacson JD, Nelson JB (2007) A phase 3 randomized controlled trial of the efficacy and safety of atrasentan in men with metastatic hormone-refractory prostate cancer. Cancer 110:1959-1966.

17. Russo F, Bearz A, Pampaloni G (2008) Pemetrexed single agent chemotherapy in previously treated patients with locally advanced or metastatic non-small cell lung cancer. BMC Cancer 8. 
Figure 1
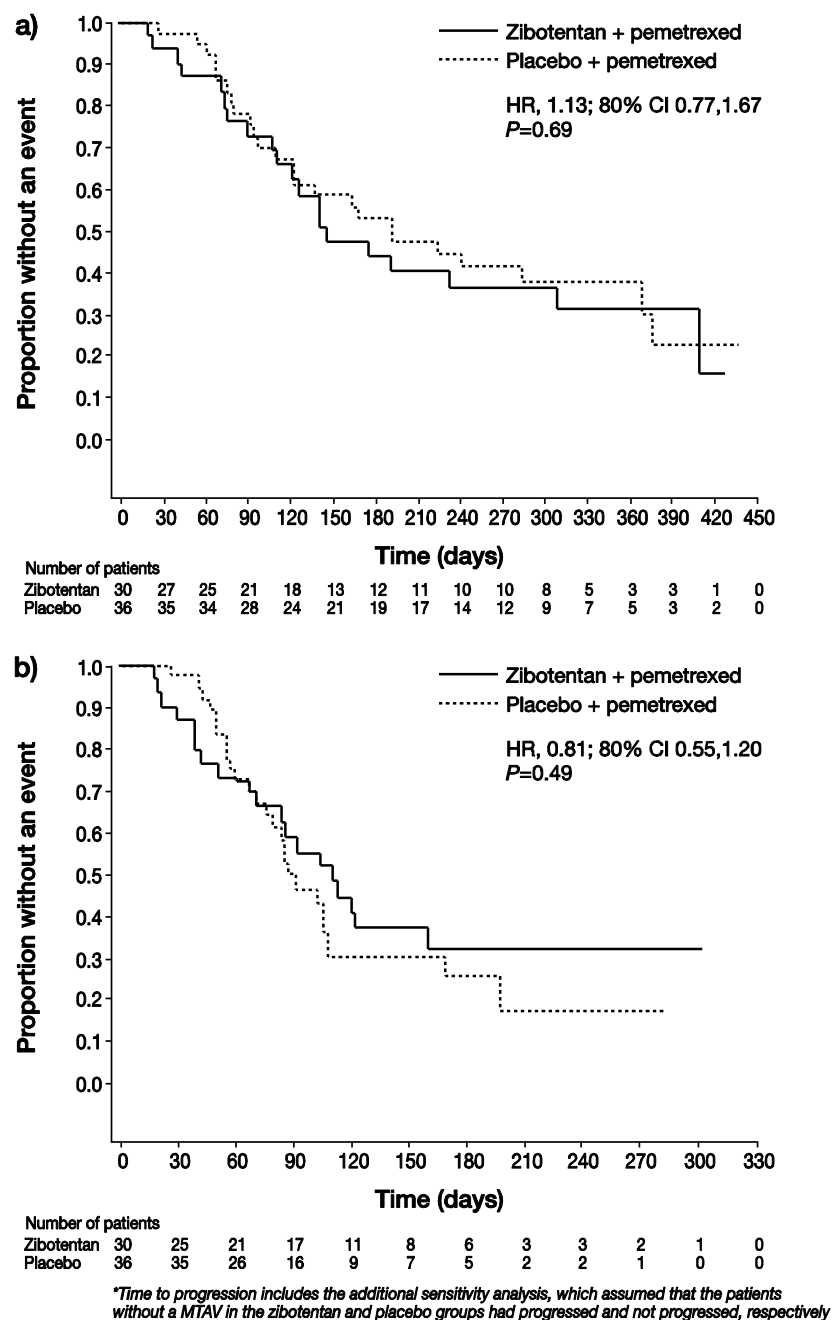
Figure 1
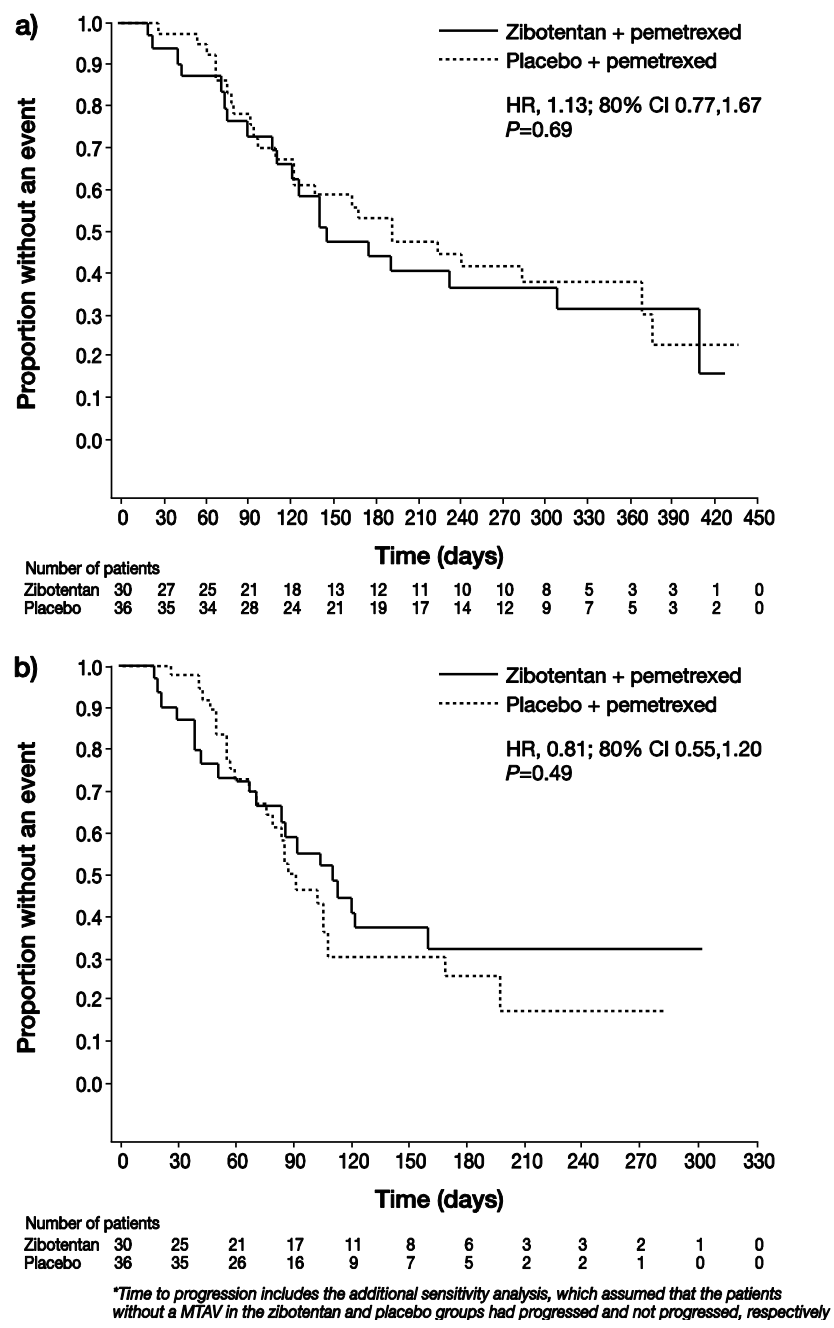